\title{
GI-MS48-P01 | HOW BEST TO SEARCH AND LOOK FOR CHAOS IN CRYSTALS BY
}

\section{DIFFRACTOMETRIC METHODS}

Kodess, Boris (FSUE "VNIIMS", ICSE, Moscow, RUS)

In a crystals there are structural defects or the local disorder due to impurity atoms. The existing and developed models of the crystal structure describe the accumulation of defects and originate of a web of defects, which condition the transition to a quasi-crystalline or amorphous state of substance. How accurately find these defects and determine a signs of transition from strong order to weak turbulent state or strong and transformative, and sometimes destructive chaotic behavior of some characteristics of crystals?

The defects classification and diffractometric methods is related to the length scales of the phenomena in crystals. An increase in the number of disturbances in the arrangement of atoms may leads to the static displacements of atoms. The displacements are fixed by precision measurements of the single crystals diffraction pattern and/or by the results of low-temperature measurements. With have an increase in scale and the number of defects, a microstructure arises in the samples. Microstructural defects are analyzed by measuring the integral width of Bragg reflections. The next type of defects is associated with reaction or adaptation to high surface tension and/or to chemical exposures. These defects are determined by the changes angular positions results and/or the time series of these angular positions observation. For example, we has been observed oscillatory changes of the angular positions during the long-time series (from 250 to 950 hours) for YBCO breathing-crystal [1]. Another examples is the chaotic behavior in the vicinity of phase transitions in the KDP, others ferroelectrics, $\mathrm{Pd}(\mathrm{H}: \mathrm{Me})$ and some bio-crystal. 